\title{
6. When the cat has been let out of the bag Managing kinship trouble
}

In his ethnographic study of anonymous sperm donation in China, anthropologist Ayo Wahlberg points out that "[b]oth recipient couples and donors engage in various negotiations of who to confide in" (2018: 177), instead of sticking to "absolute secrecy or confidentiality" (ibid.). Wahlberg argues that it is "the management of who should know what" (2018: 171) that is their biggest concern. Parents want to avoid having to deal with their social environment's gossip, and donors want to protect "their imagined future family life" (ibid.) from any disruption that could occur if children conceived with their sperm would contact them one day. Referring to anthropologist Sebastian Mohr's (2015) exploration of how Danish sperm donors make sense of the connections between them and the children conceived with their donations, Wahlberg interprets this as an effort to manage any potential "kinship trouble" (2018: 171), which can "arise[...] when connections to third-party children are negotiated in particular cultural and juridical settings" (ibid.). ${ }^{1}$ Clinics are also involved in the process of managing kinship trouble, as they ensure that donors and recipients stay separate. However, Wahlberg points out that "further kinship trouble" (2018: 177) cannot be precluded "should the proverbial cat be let out of the bag" (ibid.).

In the case of my interviewees, the cat had already been let out of the bag. They thus looked back at how their parents had imagined and managed kinship trouble in the past and critically evaluated their decisions regarding disclosure. Some

Mohr argues that donors in Denmark, which allows both anonymous and non-anonymous donations, face kinship trouble, as they are "in a cultural and organizational context that offers different and contrary ways of how to make connections to donor-conceived individuals meaningful" (2015: 470). Sperm banks and Danish laws expect them to conceive of these relations as "contractual relations" (2015: 474), whereas "the dominant kinship narrative" (ibid.) urges donors to interpret them as belonging to the realm of family relationships. Mohr argues that donors "walk unexplored territory, not really knowing how to ascribe meaning to connections that defy existing classifications of kinship" (2015: 481). He suggests that although kinship trouble is commonly perceived as negative, it "might open avenues for new types of sociality not grounded in traditional concepts of being related" (2015: 482). 
of them had learnt in conversations with their parents that they had followed the instructions of their doctors, who had advised them to simply forget the whole treatment. This used to be a common practice (Dempsey and Kelly 2017: 205). Others had been told by their parents that they had been indecisive immediately after the treatment and then simply missed the opportunity to tell their children. Since their parents had opted for donor conception in a context where there was a clear "cultural expectation that men uphold the patriarchal status quo through their biological contribution to the creation of a child" (Becker 2000: 134), the danger that the donor posed to the patriarchal family order had to be minimised through secrecy (and anonymity). However, in most cases they had already told others - mostly inside, but sometimes outside the family, even if they did not necessarily intend to tell their children about it. I found that a central question people asked themselves was not only who the donor was, but also who else knew about the circumstances of their conception - and who else within and outside the family should be told about it. At times, they were even more concerned with these questions than with the identity of the donor.

The importance of finding out who else knew and actively managing kinship trouble by telling or not telling others indicates that constitutive knowledge matters in ways that are not fully reflected upon in policies and debates about openness and access to information. The examples discussed in this chapter illustrate that anonymity, secrecy and information have the potential to become problematic in ways that are not accounted for in policy documents and discussions regarding the individual's right to know. Moreover, the decisions people make when it comes to kinship trouble are often far more complex than the ideal of honesty would suggest. In my analysis, I am again inspired by Konrad, who has analysed "right to know" discussions in a different context (2005b). In her insightful ethnographic account of predictive genetic testing, Konrad argues that the "moral decision-making within and across generations" (2005b: 4) is more complex than genetic "right to know" debates might suggest. "Right to know" arguments are part of the discussions surrounding predictive genetic testing, which can determine one's personal risk of a specific disease (Chadwick et al. 2014). Proponents of these tests argue that individuals have a right to know and access information about themselves (Sheehan

In their study of the history of direct-to-consumer genetic testing, Stuart Hogarth and Paula Saukko discern two "waves" (2017: 197) of companies. Whereas the first wave that started to emerge in 1996 mainly offered nutrigenic testing and personalised dietary advice, a second wave of firms that emerged about eleven years later started to sell risk tests for common diseases that can have polygenic origins (2017: 197). Hogarth and Saukko argue that these newer firms "have been able to shift the discursive terrain on which the future of genomics is contested" (2017: 205), as they have managed to establish a view of predictive genetic knowledge as something other than frightening. They "have asserted the principle that individuals have a right to their genome" (ibid.). 
2015: 287) and maintain that "knowledge increases autonomy" (Bourdeaut 2016: 53; see also Borry et al. 2010; Prainsack 2014), which in turn is assumed to have a positive impact on important life decisions.

In her analysis of the experiences of families affected by Huntington's Chorea, an inheritable disease that can be detected in pre-symptomatic persons, Konrad points out that discussions about a genetic right to know are largely based on a framework in which the rights of an autonomous individual are dominant (2005b: 88). She argues that the debates fail to take into account that predictive testing does not just raise questions for the individual that is being tested. Instead, it can have implications for other relatives as well: if one person is found to be a carrier, then any family members to whom they are genetically related are at risk too. This can lead to serious "disclosure dilemmas" (2005b: 4). Konrad gives the example of a woman who tested positively for Huntington's Chorea but decided not to tell her healthy father, who had already lost her sick mother to the disease. Konrad concludes that "considerations of care and kindness [...] seem more relevant to her than the disassociated norm of straight talk imbibed in the principle of honesty" (2005b: 92), and I found the same to be true for the way my interviewees approached telling others.

I will start off by discussing the preoccupation of my interlocutors with the question "Who knows what?" on a general level. In the second part of this chapter, I will examine how my interviewees themselves made decisions about whom they wanted to tell, and what kind of kinship and friendship trouble they envisaged and experienced in that process. Following from that, I will turn towards the situation of those whose siblings had either not yet been told that their parents had used donated gametes to conceive them, or who had only found out later on. In the fourth and last part, I will examine how my interviewees felt about telling their non-donor-conceived children about their donor-conceived origins. This will show that the effect of constitutive information extends into people's kinship future.

\subsection{Who knew what and when: Broken trust and foreign children}

Several people mentioned that immediately after being told about the circumstances of their conception, they had asked their parents who else knew about it. To find out that relatives or close friends of their parents had been informed years ago was a very painful experience for many. It could reinforce the feeling that one could have been told way earlier, which in turn reinforced the feeling that one should have been told early on. The more people had already been informed, and theoretically could have talked about it, the more likely a different outcome and an earlier disclosure would have been. But it could be just as painful to learn that one's parents only told a grandparent, aunt or uncle who then remained silent, especially if peo- 
ple had a close relationship with this person. My interlocutors often described that this had impaired their ability to trust their parents in particular. Trust is commonly seen as deriving from kinship (Carsten 2004: 142), and it is mostly accepted that "kinship forms an archetypical sphere of trust" (Zitelmann 2018: 66). In the following pages I will give two examples of people for whom broken trust and the subsequent management of kinship trouble played an important role. I will then investigate why strict secrecy was rejected, especially by those who did not believe that using donated gametes inevitably causes kinship trouble.

For Timothy Parsons, who was in his mid-2os and had been conceived in the UK shortly before the HFEA was founded, it was particularly important to find out who knew, rather than focusing on the identity of his anonymous donor. At the time of the interview, he had known for about ten months that he had been conceived with donated sperm, and he was not completely sure whether he should even try to find his donor. Unlike those who had known for years or decades, and who seemed to be experienced in telling their story, it was a new experience for Timothy to talk about it extensively. He described our meeting as a useful "preparation" should he meet his donor sometime in the future, as such a meeting would be "immeasurably more difficult" if he had not previously talked about it with anyone. The way he jumped from one topic to the next seemed to reflect how much the news about his origins still stirred him up. At several moments during the interview, he seemed to be close to tears, which matched his self-description of being "a very emotional person" and of having been "emotionally torn" when his mother spontaneously told him that he was donor-conceived. Timothy himself pointed out that his life had already been quite "unstable" prior to finding out because he worked freelance. Since work commitments could come up at short notice, he had informed me by email that he could not plan the interview long in advance. After he had already postponed a first meeting, Timothy emailed me one afternoon that he would have time the following day. Fortunately, I had no plans yet, and we agreed to meet up in his favourite café. It was very small but well attended, and I was not sure at first if Timothy would feel comfortable enough with so many people to talk openly. He had already informed me that it was extremely important for him to remain anonymous, which was why I was surprised about the meeting place he suggested. In the café that he often visited, the probability that those present might listen in on our conversation and might even know him seemed to be relatively high, despite it being situated in a big city. While speaking in a low voice at first, Timothy did seem to feel a lot more comfortable later when the room emptied, which was reflected in his voice becoming louder and him getting more emotional. As I found out during the conversation, his anonymity was a concern to him because his father's family did not know he was donor-conceived, and Timothy wanted to avoid them finding out. While I had feared from his inquiries about my anonymisation practices that he probably would not be very open, my fears turned out to be unfounded. 
Timothy mentioned that he had been shocked when his mother spontaneously decided to tell him about his donor-conceived origins as they were driving her car, and he was sure he would have processed the news better if he had been told in a more planned way. He remembered that there had been three things he immediately wanted to know: who else knew that he was donor-conceived, whether his younger brother (who was also donor-conceived, but with sperm from a different donor) already knew, and who his "biological father" was. Whereas his mother could not tell him who the donor was, she did tell him that while his younger brother had not been told yet, her family members, to whom Timothy had always been very close, had known for a long time. Finding out who else knew became the basis for a reassessment of both his life and his family relationships:

Timothy Parsons: "You're trying to figure out who the hell am I, who can I trust, who can I talk to, who do I need to feel accepted by, and I guess I was finding out who knew because I felt it was such big information, and I then I want to know who knew before I knew because obviously it says a lot about, I kind of felt cheated in a way because I felt like most people knew, but I didn't know, and then my mom and my dad, I felt like they'd trust me, they would tell me this kind of information before they'd tell anyone else."

While others were very angry about their parents' secrecy, Timothy showed understanding for his parents' decision not to tell, noting that his family had already been "quite broken as it was" due to his parents' early divorce. He interpreted their decision as an attempt to protect him and his brother from further damage. However, ten months after the first conversation with his mother, it still hurt him that the majority of his maternal relatives had known but had never mentioned it to him or his brother. Finding out who else had been informed had been "a really big thing" for him, although his intention had never been to talk to his relatives about the circumstances of his conception. His trust in his maternal family and in his parents was still shaken, despite his understanding and his decision to forgive them. However, his anger and disappointment did not lead to him severing ties with his family. Instead, he made a conscious decision to practice and cultivate trust by spending more time with his family and tried to see all of his relatives regularly, believing that not getting in touch with them would only make him angrier.

Unlike Timothy, Lindsay Billington knew that relatives on both sides of the family as well as several of her parents' friends and colleagues had been told before she herself was told by her mother and father shortly after her twenty-first birthday. Lindsay reasoned that her parents' frequent visits to a clinic in the early 1990s, combined with her mother suddenly getting pregnant after trying unsuccessfully for a long time, had almost forced her parents to tell since "it would have seemed strange if you try for seven years and then you conceive naturally without help". In fact, her parents eventually decided to talk to Lindsay precisely because people in- 
side and outside the family already knew about it. Her paternal grandmother had never agreed with donor conception, and they were afraid she might tell her out of spite. They were also afraid that a man outside their circle of friends might tell her, as one of Lindsay's uncles had warned them that this person had found out. She was noticeably hurt by her father's confession that he would never have told her if it had not been for her grandmother "acting up" and her uncle's colleague finding out. Her own initial feeling of shock gradually changed into anger as she struggled to come to terms with realising that people remained silent even after she had been told:

Lindsay Billington: "I mean I wouldn't be bothered that somebody else knew, I was bothered that all my family knew and didn't tell me for my whole life, and that since I've been told, there has only actually been ... one of my uncles and my brother, one of my brothers [from her father's first marriage, not donor-conceived] who have dared to actually talk to me about it, like no one has mentioned it to me." Amelie Baumann: "Although they know that you know?"

Lindsay Billington: "Yeah, even though they know [...] it is hard to know that all your family knew and look at you, and they don't say anything because it was such a big secret in the family, and you just think, two of my mom's best friends knew, and then you find out that in fact all of her friends that she used to work with knew, and you just think, why did everyone know, but not me?"

In order to find out whether it was known "further in the family than just the grandma's siblings", Lindsay eventually told one of her cousins. As it turned out, she had not been told, and Lindsay swore her cousin to secrecy. Lindsay's trust in her parents had been unsettled, and the sense of betrayal that many people talked about was particularly strong in her case. She described herself as having been "a trusting person" prior to finding out and mentioned that she had "lost trust in other people". Her parents had repeatedly tried to raise the issue over the past two years, but Lindsay had blocked the conversation time and time again, as she did not feel comfortable talking to them about donor conception.

The issue of lost or broken trust that appeared in both Timothy's and Lindsay's account was a common theme in many interviews, with people frequently mentioning that they feared that their parents might have even more secrets. Trust, which my interviewees deemed essential for family relationships, has been described by Niklas Luhmann as a complexity-reducing mechanism (2017). Similar to hope, which is directed at an uncertain future (Mattingly 2010: 15; see also section 7.4 for an exploration of the connection between hope and uncertainty in the context of voluntary registers), trust has a specific relation with what is yet to come. Since "not all futures can become the present and hence become the past" (Luhmann 2017: 15), the future needs to be 'pruned' through trust (ibid.). In the case of people who found out that their parents had kept information about their ori- 
gins from them for years or decades, while mostly telling others, their ability "to enter a social relationship on the expectation that the other will act according to one's expectations" (Müller 2013: 42-43) had at the least been temporarily damaged. Since trust is integral to the way they conceptualise kinship, managing broken trust becomes an essential part of becoming donor-conceived. Although the realisation that others had already known could be painful, even those for whom this was the case often emphasised that while their ability to trust had been damaged, it had not resulted in them turning away from their parents. For example, Lindsay mentioned that although the relationship between her and her parents had changed, they were still very important to her: "I do love them to pieces, and they're my mom and dad and they always will be." I will return to the donor-conceived's use of kin terms in the last part of this chapter.

While for most of my interviewees it was painful or at least unpleasant to learn that others had already been informed, complete secrecy on the part of the parents or one parent was also considered undesirable. Those whose parents had not shared the information with anyone else sometimes mentioned that secrecy had damaged relationships in their family and especially their parents' marriage. They usually interpreted their parents' refusal to talk about it as a sign of especially their fathers' insecurity. My research contacts themselves sometimes stressed that they found their parents' secrecy unnecessary, as the decision to have a child through sperm donation was something they admired. They felt that their parents could and should be open about it. Respect was expressed both for the fact that parents had decided to undergo an elaborate and strenuous treatment and for the fact that fathers had agreed to have and raise a child with whom they were not genetically related. I suggest that the respect people voiced especially for their fathers indicates that they were aware of the "norms around fatherhood that deem genetic connections between child and father important" (Mohr 2015: 471). Since their fathers had been 'brave' enough to have children through sperm donation despite these norms, they wanted them to feel pride instead of shame. Some of them mentioned that they were grateful to their parents for having chosen this special and difficult path. They were impressed by their decision to raise, as Melanie Weber put it, "a foreign child" (ein fremdes Kind) instead of an 'own child'. Donor-conceived children can be seen as "foreign" in two ways: firstly, they are not genetically related to the man who raised them, and their roots therefore do not lie within the family their fathers are familiar with. Secondly, the anonymity of the donor means that neither they nor their parents can know where they "really come from" in terms of genetic origins. Since having knowledge "is perceived to be good in itself, alleviating insecurity and diminishing unpredictability" (Edwards 2009a: 140), genetic foreignness set up by the conditions of anonymity was interpreted as something that demands courage from parents and especially from fathers. It was seen as a step into an unknown kinship future. Although my interviewees sometimes described themselves 
as the "foreign children" of their father, it does not follow from this that they saw themselves as the children of their donor. When they spoke of the donor's "own children", they referred to those who had been conceived and raised by him. The genetic connection alone was thus not seen as sufficient for the creation of "own children", which illustrates that "what an 'own child' is and what it means is not given a priori" (Melhuus 2012: 25).

Sabrina Frey from Germany was one of my interviewees who believed that fathers should be respected and admired for their decision to raise a genetically foreign child. She mentioned that her parents had in the past treated the circumstances of her conception as "a gigantic family secret" and told no one that their daughter had been conceived with donated sperm. Sabrina had learnt of the circumstances of her conception when her parents, who were now divorced, had had a fight, and she believed that her mother had told her in order to hurt her father. Her mother had become more open over the years and was interested in Sabrina's search for the donor and donor siblings, whereas her father had still not told any of his friends or relatives. He did not want to talk about it with her either. Even after more than ten years, he was still not comfortable with the thought that she knew. Sabrina reasoned that he was still afraid that she would turn away from him, despite her repeatedly trying to reassure him that this would not happen. She also guessed that he was afraid of no longer being seen as a man if others found out about his infertility. Sabrina hoped that he would overcome his fears in the future, and she was convinced that he would not encounter negative reactions if he told others, believing that "all fathers who decide to use a sperm donation because of their infertility, they really deserve a lot of respect because they decide to raise a child that's not their genetic child". She admired her father's courage and felt that he was placing an unnecessary burden on himself by trying to keep it a secret "come hell or high water" (aufBiegen und Brechen). Sabrina was of the opinion that the decision to have a child with donated gametes was something to be proud of and that he could and should tell others about it: "Maybe he would just make the experience of people telling him, 'What you did is great', something like that. Or something like, 'I would not have had the courage to do that', maybe he would get a reaction like that." Overall, she felt happy and proud about being a "Wunschkind", a child that had been wished for. Sabrina was convinced that "there's nothing better than that". ${ }^{3}$ For this reason, she believed that the use of donated gametes did not have to be concealed: “That's why I don't understand why you have to hide it. It's nothing bad." that his/her parents had wanted and 'planned for' but has a more emotional and less technical connotation. 
Several people also argued that nothing better could happen to a child than to know it had been wanted this much, instead of being born as a result of an 'accident' or because one's parents felt pressured to have children. ${ }^{4}$ However, the question of whether a decision to conceive with donated gametes was something admirable (for which donor-conceived people should be grateful) or not, was highly controversial. In Germany, these debates were particularly evident in the way in which the term "Wunschkind" was evaluated and used. While Sabrina and others emphasised that a donor-conceived child was a "Wunschkind", others rejected the term as irrelevant and offensive. For them, the term symbolised that parental desires were respected more than children's rights. Not everyone was of the opinion that they were particularly wanted. While some emphasised that they felt very loved, others commented that their parents would have preferred to procreate with their own gametes, and that they therefore did not feel wanted at all.

\subsection{Who should know what: Relations between concealment and revelation}

Apart from trying to figure out who else knew, my interlocutors also engaged in the management of kinship and friendship trouble by deciding whom they themselves wanted to tell, and when they should conceal the information. Even Melanie Weber, who was afraid that her parents and especially her father might get stigmatised if others found out, had told her husband and her best friend about the circumstances of her conception. Otherwise, she was very anxious to keep this information secret. Although she admired her parents for their decision to raise children that were not genetically related to her father, Melanie had initially had concerns about joining the mailing list of Spenderkinder. She had been very afraid that other members of Spenderkinder might misuse the information about her conception, ${ }^{5}$ and that it might 'escape' the safe space of the mailing list and reach the outside world. In general, my interviewees mentioned that they had at least told their close friends that they were donor-conceived. Many felt that it was such an important part of their lives that they did not want to hide this information from people they were close to, and everyone who was in a relationship told me that "of course" they had

A similar line of reasoning has been observed by Heather Paxson (2003) in her ethnographic study of IVF in Creece. Some of the women she met felt that "their commitment to having a child using IVF makes them better mothers when many others around them appear to have a child merely because it is expected of them" (2003: 1858). Paxson argues that "the efforts they make to achieve motherhood are incorporated into a longstanding ideology of maternal suffering or sacrifice" (ibid.).

5 Melanie Weber explained her fears with reference to her work in the police force: "I just had a lot of negative experiences with people, so I always assume the worst." 
told their partner. For some of my interviewees, telling others had been a positive experience: since the people they had confided in had reacted sympathetically, they felt that their own emotional response to finding out had been justified. However, this was not the case for everyone that I met. In the following pages I will first explore why this was usually described as a very painful experience. I will then go into more detail about how Timothy Parsons, whom I introduced in the previous section, felt about telling others, and how not being met with a lot of sympathy lead to him rethinking his friendships. In the last part, I will focus on the decision to withhold information from certain individuals and explain why this can be read as an attempt to manage kinship trouble.

Several of my interviewees mentioned that they had not been met with much understanding, especially from their friends. They had the impression that others could not understand why it even mattered to them that they were donor-conceived. Above all, their friends did not seem to understand why it was painful for them not to know the donor's identity. Repeatedly I was told that others did not understand why someone would be interested in finding him. It was not uncommon for people to become more hesitant about telling if they got reactions that they perceived as unhelpful or unsympathetic. They had expected the people they were close with to understand "what it's like" since they, as their friends or relatives, had personal experience of what it is like to be donor-conceived. For them, "knowing' is achieved through experience" (Edwards 2000: 240). According to Edwards, the idea that knowledge and experience are linked is "central to the way in which people make sense of NRT [new reproductive technologies]" (ibid.). Although the people she talked to during her fieldwork were critical of certain technologies, they assumed that either being infertile themselves or knowing someone who was unable to conceive would change their perception (2000: 240-241): "An understanding of the implications of involuntary childlessness is not gained through discrete items of information [...] but is achieved through experience transferred along axiomatic links between those who are already close." (2000: 241, emphasis in original) The disappointment my interlocutors felt when not being met with a lot of sympathy illustrates that they, too, had believed that "feelings travel between people already connected" (ibid.). Their expectations were not always met. It was striking that what I was told by my interviewees does not correspond to some of Spenderkinder's statements: on its website, Spenderkinder emphasises that its members cannot report any negative experiences with regards to telling others. ${ }^{6}$ Given the association's emphasis on the importance of telling donor-con- 
ceived children early on, comments about members never or hardly ever having had any negative experiences are not surprising. They strengthen Spenderkinder's insistence on early disclosure.

Although it was experienced as painful and disappointing when others did not empathise with their feelings of hurt and betrayal, being donor-conceived was also interpreted as something that formed the basis for appropriate opinions and judgements. It was common for people to mention that, as Becca Haste from the UK put it, "people who haven't been in it, they wouldn't know how to react". For this reason, it was sometimes seen as a little surprising that others who were not "in it" had little or no understanding of their own, more critical opinions. Repeatedly my interviewees told me that their own opinions on gamete donation had changed after they had found out that they were donor-conceived. Jade Foster, for example, told me that she used to toy with the idea of donating her own eggs: "I was thinking, 'It would be a nice thing to do, I can help people out.' And then I found out, I started researching, no, [laughs] it's not something I want to do at all, I don't want to become a part of that system." While her own opinion had changed, her best friend, who was gay, was still in favour of gamete donation and anonymity:

Jade Foster: "When I told her how I was conceived, she was like, 'Oh, I don't want my child finding out, l'll just go to America, l'll get the sperm shipped from America because I don't want my kid finding out at all, and me and my wife, we're their parents, we don't need to find out anything. Which bugs me because she can see how I felt about it, but it sent her in a completely different direction."

While Jade and her friend were still close, friendships could also change if expectations in terms of sympathy and empathy were not met. The way in which telling others could become the basis for the re-evaluation and reconfiguration of relationships became particularly clear in the case of Timothy Parsons. As already mentioned in the interview passage quoted at the beginning of the last section, "who can I talk to" was a question that had come to his mind right after he had been told. Timothy felt a great need to tell people about the circumstances of his conception "because that's who I am and I can't deny it, that's who I am, and I feel like I need to live who I am". At the same time, however, he had been hurt by the unsympathetic comments made by some of the people whom he had already told. He mentioned that the "classic" comment that he tended to get was "Oh but come on, you've still got a dad". He acknowledged that this was said in order to make him feel better but argued that it was essentially just a sign of others not being able to appreciate

been (sometimes implicitly) told not to tell others. However, the post also mentions that their experiences with telling others have not been negative: "Nobody encountered negative reactions, the only negative experience that was reported was the feeling of not being understood." (Spenderkinder 2014b, author translation) 
what being donor-conceived really meant for him. Telling others was still a big step for Timothy when I met him:

Timothy Parsons: "And then you have a whole choice about who you're going to tell, and I think that's one of the biggest things, is who you're going to tell, because then, [sighs] when I first found out, when I was making that decision [sighs] it felt like a massive trust thing, who I was going to tell, and if I felt like I could have trust in you to tell you, and then how you reacted to that, it turned into a really big thing, because it's like oh l've told you, and then if you show me care or compassion, it's kind of like, alright, now I can trust you. And then if you just don't show me care and compassion, it's like alright now l've entrusted in you this information that is to me the most important information that l'll ever find out, and if you don't show any compassion after all or call me afterwards to see how I'm doing or any of that, then I just feel like I can't trust you anymore. No matter how or what our previous relationship was [laughs] which is something that I never thought would happen."

Since many of his friends' reactions had not been compassionate, Timothy distanced himself from some of the people with whom he had previously been close. He had been anticipating sympathy and support but had instead come to the painful realisation that his expectations were not always met. Timothy felt that it had become difficult for him to get to know new people since he had been told, as he found it difficult to trust others. However, he felt that the ability or willingness to confide in others was fundamental to building close relationships since "it's so close to my identity, that for me not telling them, it feels like I'm not keeping them close [...] I'm keeping them at arm's length". His remarks tie in with what Weston (1991) has written about coming-out narratives of lesbian women and gay men. She found that the people she spoke to "experienced unspoken truths as things that come between people, barriers that interject "distance" into relationships" (1991: 50). Weston argues that "[i]n coming out, a person acts to create a sense of wholeness by establishing congruence between interior experience and external presentation" (ibid.), which corresponds to Timothy's desire to tell people and "live who I am".

Whereas several people described how they had over time become more careful because their friends' and/or relatives' reactions had been disappointing, others who had known for a long time mentioned that for them, telling others had over the years ceased to be an emotionally charged event. However, this did not necessarily mean that they wanted everyone to know, and most people chose to reveal information in one situation and decided to conceal it in another. This was the case for Sarah Holmes, who had known for about two decades that she was donorconceived. She told me that she had initially followed her parents' example, which had been "modelling secrecy", and hardly ever talked about the circumstances of her conception. Whereas her parents had not told anyone apart from her maternal 
grandparents, Sarah herself had gradually become more open as she had gotten older. She brought this up when I asked her whether she had told her friends that she was donor-conceived:

Sarah Holmes: "Over the years, I've become a lot more comfortable with being donor-conceived. And I feel more comfortable talking about it. I think I've processed a lot over the years. If I was talking about it when I was in university, when I was 18, it still felt like a big secret, and it felt like I shouldn't be talking about it. And it felt like I wasn't sure about what it meant to me, being donor-conceived, so l'd quite often just well up, 'Oh my god I'm donor-conceived, and I can't believe I'm telling you this.' But now it's just like, 'Meh, I'm donor-conceived, that's what it is, it is quite an interesting fact, this is who I am, do you know what that is', so I'm much more open about it now."

It was notably finding out more information about her donor, who was still anonymous at the time of the interview, that had contributed to her feeling more at ease with talking about her donor-conceived origins. However, having her real name revealed by journalists or researchers was out of the question for her, as it was still "a massive secret" within her family, and Sarah did not want them to find out "that way". Although being donor-conceived was nothing she was ashamed of, she still actively managed "who knew what and when" and had only told very few relatives. Like her, some of my interviewees were afraid that telling people both inside and outside the family would have a negative effect on their family relationships, and many worried about the way their father might feel or be treated by other people. While many of them talked about it openly with their friends, they had not told any of their relatives, as their parents did not want them to know. Although my interviewees themselves would have liked their close family members to know, they respected their parents' decision to remain silent and did not want to hurt them.

Those who talked about it a lot more openly interpreted such decisions as a sign that many of the donor-conceived were still too considerate of their parents' feelings, and that they suppressed their own needs. However, I would argue that the decision to conceal information can also be read as an attempt to protect close relationships and prevent kinship trouble. When seen from this point of view, such behaviour can be interpreted as an example for decision-making that is more complex than ideals of openness and transparency might suggest. This complexity was evident in my interviewees' ways of sharing and not-sharing information that were often seemingly contradictory and sometimes surprising. Some were very open with me but mentioned that they had only told very few friends and relatives. Others shared their experiences anonymously in online forums and magazines, but only let very few offline friends in on their secret. One person even wrote an essay about donor conception as part of her studies and mentioned in it that she was donor-conceived, even though she had only told very few of her friends. 
Furthermore, the decision not to tell someone so that others will not get hurt also illustrates that information about a person's conception was understood as something that is not only of relevance to the donor-conceived themselves. The way in which my interviewees who chose to search for their genetic origins attempted to protect their parents from getting hurt constitutes another example for these dynamics. They usually told their parents little or nothing about their search for the donor, as they wanted to avoid hurting them. They thus tried to prevent kinship trouble by concealing information. A similar observation has been made by Carsten in her research on adoption reunions (2007). She was occasionally told about adoptees that were worried about upsetting their adoptive parents and who therefore did not want to search for their birth families (2007: 419). According to Carsten, "this suggests that the constitutive effects of acquiring this information is felt to have the potential to impinge on others beyond adoptees themselves and their birth parents" (ibid.).

\subsection{Sibling trouble: Similar relations, uneven knowledge}

Brothers and sisters who grow up within the same family and have the same or different donor are generally not referred to as "donor siblings". This term is usually used for persons conceived with gametes from the same donor but raised in different families (Edwards 2013: 286). Siblingship in general has largely been neglected in the anthropology of kin relations. This tendency was arguably reinforced by a focus on reproductive technologies, which have shifted the focus of attention further towards procreation (Lambek 2011). Examining sibling relations counteracts these tendencies, as it "allows for insights into the making and breaking of kinship ties across the life course" (Thelen et al. 2013: 2). I argue that this applies not only to those who are commonly classified as donor siblings. Instead, a close examination of the descriptions of my interlocutors who grew up with siblings in their own families can also yield important insights. I am particularly interested in the experiences of those who had a sibling who was also donor-conceived. ${ }^{7}$ For them, the question of who else knew, or did not know, played a particularly central role: especially those who had been told more or less spontaneously had often found out in the absence of their sibling. Some of my interviewees had known about the circumstances of their conception for several years, and their brother or sister had still not been told. In addition, most of them had also learnt that their sibling had been

7 Only Becca Haste, who had a twin sister, and Tamara Haste had more than one donor-conceived sibling. 
conceived with gametes from a different donor. ${ }^{8}$ In these cases they had gained new information about the relationship between the siblings themselves, as they knew that they were genetic half-siblings instead of full siblings. Knowing more than one's sibling was described as extremely stressful and unpleasant. I will examine this discomfort using two empirical examples. In doing so I will also explore how my interviewees felt about having a different donor than their sibling, and how official regulations on anonymity can result in complex interfamilial relationships.

The uneven distribution of knowledge between her and her younger brother was extremely uncomfortable for Jade Foster, who had been told at the age of 14 that she and her brother were donor-conceived. Jade, who was 18 years old, believed that her parents had always intended on telling her once she was at an age when she would have "an understanding of genetics and of conception". However, she did not think that her parents had made the right choice: "It makes me annoyed that it was kept from me, it feels like it was a secret that they had that power to tell me when they wanted." Her brother, who was five years younger than her, had not yet been told. Jade had learnt from their parents that her brother had been conceived with sperm from another cryobank because at the time of their second treatment, there was no more sperm available from Jade's donor. Although their parents had intended to use the same one, she thought that this might actually be beneficial for them. If it turned out that her brother was not interested in finding out more, then "his own journey and his feelings" would not be affected if she was ever to find her donor. Jade did stress, however, that she would feel very differently about her brother having a different donor if he had been conceived after 2005: "If they'd have waited a couple more years to have my brother, he would have access to all of his information, and I wouldn't. And that would really get to me. I wouldn't be able to handle that, if he could get it and I couldn't." If her brother had been conceived just a few years later, he would have been able to request identifying donor information

When telling me that their sibling had been conceived with a different donor, my interviewees referred to the results of DNA tests, what their parents had told them (e.g. treatment in another clinic), or a lack of similarities between themselves and their sibling. In total, four of my interviewees had grown up as only children; three had non-donor-conceived half-siblings with whom they were related either through their mother or father who had children from a different or previous relationship; two persons each had a brother who had been conceived with sperm from a different donor, and one (Timothy Parsons) or more (Jade Foster) nondonor-conceived half-siblings; one person had a younger non-donor-conceived brother who had been conceived with sperm from their father, who had successfully undergone fertility treatment after my interviewee was born; four had siblings who had been conceived with gametes from the same donor, two of whom were sisters (Becca and Tamara Haste); ten of my interviewees told me that their only sibling had been conceived with sperm from a different donor. Those who had a sibling that had been conceived with the same donor had all found out that they were donor-conceived either at the same time as their sibling, or just before them. 
from the HFEA. Their respective possibilities of obtaining information about their donors would have been unequal. This illustrates that different legal regulations concerning anonymity can lead to complex relationships within a family and have the potential to cause "sibling trouble".

Ever since Jade had been told about the circumstances of her conception, she felt like she was complicit in her parents' secretive behaviour. She was deeply uncomfortable with that and with her brother not knowing. Jade believed that him being told would make them closer, as they would then share the knowledge about the circumstances of their conception. Sharing has been described as a key mechanism for the forging of sibling relations (Thelen et al. 2013; Pauli 2013), whether it be shared parentage or shared experience. If one of two siblings does not know of the circumstances of their conception, the two are not able to forge siblingship based on the facts of donor conception. They may be known to each other as siblings, but not yet as siblings who are both donor-conceived. Their commonality in terms of the circumstances of their conception can only become effective and activated if both siblings know about it. Although Jade was in a position where she could choose to tell her brother, she had chosen not to do so. She felt that telling was their parents' responsibility, which was typical for those of my interviewees who had been told before their sibling found out. ${ }^{9}$

How much having an uninformed sibling could put a strain on people became particularly clear in the case of Timothy Parsons, whose mother had spontaneously told him about his origins without his younger brother being present. Their father, from whom his mother had long been divorced, had been out of the country at the time; Timothy told him a few weeks later that he had been told. As mentioned earlier, he wanted to know immediately whether his brother already knew. It turned out that their mother had not yet told him that he and Timothy were donor-conceived. She was of the opinion that her younger son should not be told immediately, as he was still in his final year of university. She feared that finding out the truth would unsettle him too much. In the following months, Timothy experienced what he described as an almost unbearable "limbo period":

Timothy Parsons: "I had to wait six months to tell my brother. The first month was probably the hardest, but then the next six months, I decided to go away January, February, March, I went out of country for a bit, which was kind of nice, but then I came back and it all hit me like a ton of bricks because it was kind of like, I've

9 Only two of my interviewees had told their siblings themselves. In both cases, the parents had originally planned to tell their children at the same time. One of them was Diana Kraft. After Diana's mother had told her, Diana spontaneously told her brother about it over the phone. Since both knew that their mother was planning on telling them something important, he had not been shocked. Nadine Fuchs had told her brother about it without their parents being present, presumably because he had hardly any contact with them. 
just been ignoring this, which is great to ignore but then I really struggled when I came back to kind of accept what it was that I was going through. And the fact that I couldn't speak to my brother about it was really, really, really, really hard, it's excruciating because I couldn't concentrate on anything. At work, I couldn't concentrate on anything, in my personal life, I couldn't concentrate on anything, I was just in this limbo period. I'd say that period between November and June, finding out and telling my brother, honestly, when I look back on the story, it would be the 25 years up until I found out, then the six-month period where I couldn't speak to anybody, and then the day I could actually tell my brother and move on from there because I had to. So, since I told my brother in June, I've been trying to just rebuild my life essentially."

The use of the limbo metaphor which took up a central place in his account has been explored by Becker in her monograph Disrupted Lives (1997), in which she explores "the process by which people attempt to create continuity after an unexpected disruption to life" (1997: 4). She points out that for those who experience a disruption such as infertility, their "culturally derived sense of being propelled through time" (1997: 120) has stopped. Becker suggests that the limbo metaphor helps them "to begin the slow and painful process of re-establishing a sense of future and a sense of order. By understanding this period of disorder and disaffection as temporary, they were able to better endure their sense of disruption." (Ibid.) For Timothy, the limbo began by him receiving information that was constitutive not only for himself but also for his brother. When Timothy eventually managed to "orchestrate a way of telling him in the best possible circumstances", which was in sharp contrast to the completely unplanned way in which he himself had found out, the "limbo" came to an end. Although his mother took over the part of actually telling his brother, he had ensured that he would be close by, and his brother called him soon after he had been told.

Interestingly, Timothy pointed out that he felt that they were "in it together in a way", although his younger brother dealt with the news completely differently. Since he had never been particularly close to their father and, according to Timothy, was not at all an emotional person, Timothy believed that he was still "denying things a little bit" and had not "really truly accepted it for what it is yet". To Timothy's relief, his brother had not been angry with him when he learnt that Timothy had already known for several months. They now had the same knowledge about their origins, and sibling equivalence had been restored, at least to some extent: like Jade and her younger brother, Timothy and his sibling had been conceived with sperm from two different donors. Since his mother had miscarried after having been inseminated with semen from the same donor the second time, his parents had, as Timothy put it, "changed sperm" for his brother. While Timothy had been conceived before the establishment of the HFEA, his brother had 
been conceived just after 1991. This meant that his brother, unlike him, would be able to obtain information from the central register, which Timothy described as a "strange" thought. A certain inequality between the two brothers remained. Nevertheless, Timothy felt that he could now "move on a bit". After finding out that he was donor-conceived, he had gotten back together with his ex-girlfriend, which he interpreted as his attempt to go back to "a time when I didn't know". Making sure that his brother knew gave him "the strength to actually leave that relationship behind". The need to "move on" was also addressed by others whose siblings did not yet know of their origins. Many had the feeling that they could not really process the news and, for example, could not start their search for their donor as long as their sibling did not know (see for example David Winkler in section 8.4).

These examples suggest that having a sibling who had not been told brought an element of unevenness into a relationship that is generally considered to be characterised by equality, at least in Euro-American kinship thinking (see also section 7.5 on donor siblings). Kinship trouble is caused not only by what the donor-conceived themselves do not know but also by them knowing that others do not know where they come from, and how they are related to them. However, the "ideal of sibling equivalence" (Konrad 2005b: 133) may not be fully restored even once everyone is informed. ${ }^{10}$ Different laws on anonymity can lead to different 'starting points' in terms of the possibility of gaining knowledge. ${ }^{11}$ The examples discussed in this section thus illustrate that anonymity and its transformation, notably in legal terms, not only affect individuals but also have the potential to impinge on intra-familial relations.

While having donors that donated under different regulatory frameworks was imagined or described as challenging, having been conceived with sperm from two different donors was usually interpreted as something that would actually prevent sibling trouble. People felt that difficulties might arise if one person was more interested in the donor than the other, and several of my interviewees did actually tell me that they were more interested in finding their donor than their sibling. None of those who reported of such interfamilial differences had been conceived

10 This ideal has been explored by Konrad (2005b) in the context of predictive genetic testing. She found that those who had not yet undergone testing after a parent had tested positively for Huntington's Chorea were oftentimes worried about how the results would affect their relationship with their brother or sister if their sibling had different results. Konrad suggests that "the sharing of uncertainty and the joint propensity to misfortune between siblings" (2005b: 111) may even "comprise[...] the primary kinship link, the strongest tie" (ibid.).

11 This may in fact not only be the case with siblings conceived under different legal frameworks: for example, Jade Foster and her brother were both conceived after 1991 with sperm from two different donors. Theoretically, one of the two donors could make himself identifiable while the other remains anonymous. In this case, only one of the siblings would be able to obtain identifying information from the HFEA. 
with the same donor as their brother or sister. While recipients might think of having several children with sperm from the same donor as "a strategy of damage limitation that minimizes exposure to the unknown" (Newman 2019: 714), my interviewees tended to think about their 'divided' origins differently. They saw it as a situation that had the potential to protect an uninterested sibling from being 'exposed' to that which they attempted to make known.

In contrast, the decision to have several children from the same donor can constitute recipients' attempt to avoid kinship trouble and protect their children from not being perceived as real siblings. Especially for lesbian couples who run the risk of not being recognised as real families, choosing the same donor can be a legitimising strategy and a means "to construct and demonstrate a sibling relationship" (Nordqvist 2012: 652), with siblingship being defined as a (full) genetic relationship. Such a view was also partly present in my material; for example, some of my interviewees mentioned that they were not very close to their sibling and were very different from them. They attributed this to the fact that they had been conceived with sperm from two donors, thus interpreting full genetic relatedness as a prerequisite for close sibling relations (see for example David Winkler in section 5.2). Having been conceived with sperm from the same donor could in turn be experienced as something that could create sibling unity, as I will explore in more detail in section 7.5 when introducing Tamara and Becca Haste, two donor-conceived sisters from the UK. For them, it was the fact that they had been conceived with sperm from just one donor that had prevented sibling trouble. Tamara pointed out that finding out that they had been conceived with sperm from different donors would have been "upsetting", as it might have resulted in only one of them finding their donor which, she believed, would have been "really bad" and "dividing".

\subsection{The offspring's children: Managing intergenerational relations}

As Edwards has pointed out, "reproduction is always about more than conception" (2000: 30). A child's birth "reproduces not only a new human being but also significant social relationships" (ibid.). While the donor-conceived may not be born as parents, it was striking that even those who did not yet have their own families thought about what the circumstances of their own conception would mean for their future children and their children's future grandparents. Sometimes it was the potential for "significant social relationships" that was significant. This section thus shows that complex intergenerational relations arise in the context of anonymous gamete donation. The degree of closeness and importance of these relationships, which my interlocutors determined in varying ways, had an influence on how concrete decisions were made on the question of whether one's own children should be told. Although there was a strong tendency to tell them, opinions 
and practices differed. I will start of by examining what shaped the practices of telling and the stories people formulated for their children. I will then explore why telling could also be seen as problematic and discuss how this relates to the way people conceptualised their child's kinship network. In the last pages, I will give a concrete example of intergenerational kinship trouble caused by anonymity, and also explain why relationships with donors were, at least by some, expected to be unproblematic.

The way people told or planned to tell their children about the circumstances of their own conception was very much shaped by what they thought about disclosure and donor conception in general. It was emphasised in particular not only that children should be told about their origins as early as possible but also that donor-conceived adults should tell their children as early as possible that they, as their parents, were donor-conceived. My interviewees often emphasised that they wanted it to be as "normal" and "natural" as possible for their children, instead of turning it into a burdensome and potentially dangerous family secret. When I asked them what they would advise people who were thinking about having a child with donor gametes, these points were almost always part of their replies. In addition to the donor's identifiability, early disclosure and general openness were the criteria mentioned when it came to how donor conception could be an ethical practice.

In some cases, it was striking how similar the stories that my interviewees told their own children were to those presented in 'disclosure books' for recipient parents today. Klotz found that these books, which are oftentimes written and published by concerned groups such as the DCN, "were key to how the canonical idea of (passive or active) early disclosure was facilitated through the groups of parents (and children) involved with DI" (2014: 208). ${ }^{12}$ The English and German books she analysed, which parents used to tell their children about their origins, had very similar storylines: "There are one or two parents who would really like to have a child; children are normally conceived by egg and sperm; there is a difficulty with this because of reason X; but then the parents - or a doctor - have an idea; the parents get help; "you" are born." (Ibid.) The books were structured along "three central themes: love, biological reproduction, and assistance" (2014: 209).

The story that Sarah Holmes, who had joined the DCN long before she started her own family, had told her eldest son had a very similar storyline and message.

12 Klotz found that at the time of her research, "the concept of an early active disclosure by talking to toddlers about gamete donation" (2014: 207, emphasis in original) was more dominant in the British than in the German discourse. Those who chose a more passive approach would "start telling once their children start asking their first questions about reproduction" (2014: 202). 
Sarah was in her mid-3os and had known about the circumstances of her conception for over two decades. Through her longstanding and active membership in the DCN, she had met and talked to many families who propagated and practiced early disclosure. Sarah described how the organisation's pro-openness stance had given her "another model of how things could be". This "model" differed from the behaviour of her parents, who had kept the treatment with donor sperm secret. For years after Sarah's mother had told her about it during an argument when Sarah was 13, they did not want to talk about it with her. She herself had only begun to deal with it differently and openly when she had moved out of their family home and started her studies (see also section 6.2). At that time, she had also joined the DCN, which she had discovered online. Meanwhile, Sarah had become a mother herself. After commenting on the importance of early disclosure, she mentioned that her son already knew that his mother had been conceived with donor sperm:

Sarah Holmes: "I've told my son from the age of about three or four and simply said, 'You need eggs and seed to make a baby, the eggs come from the mommy, and the seed come from the daddy, so we used mommy's egg and daddy's seed to make you. But when nanny and grampy wanted a child, they used nanny's eggs and granddad's seed didn't work, so they went to the doctor's and they used a kind man [...] they borrowed his seed and used it with nanny's egg, and it made mommy.' So, although he doesn't know about genes, and he doesn't know that he's not genetically related to his granddad yet, he knows that a kind man made mommy, so l've always been very open with him. And eventually that will all fall into place as he gets older. It won't be a big secret or a revelation for him. It will just be pieces of information being added over time as he gets older."

Whereas Sarah did not mention that she herself had used a DCN book to tell her son, Jessica Robertson from the UK had used one of the association's books to tell her daughter about her origins. Besides, she had also bought another book to tell her about her own reproductive plans. Jessica tried to get pregnant with donor sperm at the time of our encounter. She had been divorced from her daughter's father for several years and by her mid-3os had decided not to wait any longer for a partner to have a second child, as she feared she might "run out of time". Jessica had told her daughter about her own origins with a disclosure book for heterosexual couples, and she had spoken with her about her plans to conceive with donor sperm with a book for single mothers. Jessica was the first donor-conceived person I interviewed, and at the beginning of my research in the UK, I did not meet anyone who did not plan on telling their child. Everyone seemed absolutely sure that the children of the donor-conceived should also be informed. Only in the course of time did I meet people who still hesitated or who pointed out potential problems. However, it was striking that even those who had not yet told their children usually mentioned that they would have preferred to be immediately open with them. 
I suggest that the importance my interviewees often attached to telling their own children, and the way some of them had already told them, underlines how much emphasis was placed on "see-through kinship" (Edwards 2018). The donorconceived did not want to repeat the mistakes of their mother and father but were determined to be good parents who lived up to their parental responsibility of being open with their children. But while they wanted to be "good parents", they also wanted to be "good daughters/sons". Thoughts about whether or how to tell one's own children did also reflect concerns about their children's kinship network, which was their own network as well. Although the ideals of openness and honesty were central, the concerns that my interlocutors expressed also show that this ideal was not all-determining in practice, and that other considerations did matter as well.

The extent to which telling one's children could be a topic that could bother people became particularly clear to me in the interview with 18-year-old Jade Foster, whom I met towards the end of my stay in the UK, and who, unlike Sarah and Jessica, did not have any children. Like others of my younger interviewees who had no intention of having a family in the near future, she did not dismiss the issue of telling her future children as irrelevant to her own life, especially since she knew that she definitely wanted to be a mother at some point. Jade was very critical of anonymous gamete donation, believing that "every child should have the right to know". She felt that the changes in the law had made sperm and egg donation "more ethical", but pointed out that "many people don't ever find out" since parents could still choose not to tell their children. Jade was particularly critical of the commercial nature of gamete donation and of "the industry as a whole", as she believed that clinics and sperm banks focused on "buying and selling" rather than caring for the welfare of the child (see also section 6.2). The way she thought about her own reproductive future as a bisexual woman was influenced by her experience of being donor-conceived and having an anonymous donor: "I'm bisexual, so I could end up with a woman, and I could end up having to look at reproductive technologies to have a child, and I think I'd have to think very carefully if I wanted to go down that route." While others were sure that they would either talk about their own origins with their children as early as possible, or at the latest when the issue arose, Jade was not yet sure what to do:

Amelie Baumann: "If you had children, do you think you would want to tell them that you are donor-conceived?"

Jade Foster: "I don't know. I've thought about that a lot because the donor is their grandparent, which is close enough that it is still a big part. And I would feel like if I didn't tell them, l'd just be doing what my parents did. And hiding something. But I wouldn't want to ruin their relationship with my dad. Or to make it seem like I was meddling with it. But then I was thinking maybe after he dies, I'd tell them, 
but I wouldn't want to then ruin his memory. I really don't know whether I'd tell them. I thought a lot about it, and I haven't reached a conclusion."

Her reflections on the subject were determined by her concerns about different kinds of relationships: firstly, she thought about the relationship between her donor and her children. She conceptualised this connection as one between grandparent and grandchildren, which she deemed as "close enough" for it to still be important. Secondly, Jade was also worried about how telling would affect the relationship between her children and her father. It follows from this that she was also concerned about her own role as mother of her children and as daughter of her parents: Jade wanted to be not only a responsible mother but also a caring daughter. She felt that she would have a responsibility to tell, as the information would concern her children's origins. At the same time, she was afraid that telling would potentially be damaging for the relationship between her children and her parents. Especially her concern about not wanting to "meddle" with the relationship between her children and her father was shared by others who were still hesitant about telling their children. Whereas my interviewees usually emphasised, notably in relation to donorconceived children, that openness and honesty would strengthen family relationships, I found that people hesitated to tell their own children because they did not want to jeopardise their child's relationship with their parents. They also wanted to protect their parents and especially their father from any hurtful comments their children might make, such as "You are not my grandfather".

Apart from her concerns about the relationship between her children and her father, Jade's considerations were also determined by the way she thought of the connection between her children and her donor and the importance she attached to this link. Like others, she conceptualised it as a relationship between grandchildren and grandparent. She envisaged a connection that tends to get overlooked in discussions about donor conception and in academic studies: the link between the donor and the donor-conceived offspring's children. ${ }^{13}$ In contrast, Carsten observed that several of the adoptees she interviewed had not told their children that they had been able to locate their birth parents and meet up with them: "As far as these children were concerned, they just had two sets of grandparents." (2007: 419) Carsten interprets their decision not to tell as an attempt "to accommodate or limit the "constitutive force" of new information" (ibid.). In contrast, several of my interlocutors thought of their donor as a grandparent to their own children. Since they felt that this was a potentially meaningful relative, sharing information with their sons and daughters became a non-trivial matter. 
Donor anonymity was seen as harmful not only because it kept the donor-conceived from knowing who they were but also because it meant that the children of the donor-conceived could not know all of their roots. Tamara Haste from the UK, who had just finished her studies and had no children yet, saw this as one of the overlooked consequences of anonymous sperm donation. She was no longer in contact with the man she had previously believed to be her father. While she hoped that the man she would have children with would "know his heritage, and that's all fine there", this was not the case with her. As a result, she feared that her children "won't know a quarter of their heritage, it will completely blank to them". In general, policies and regulations on information sharing and openness prioritise the connection between the donor-conceived and the donors (Gilman and Nordqvist 2018; Raes et al. 2013). The relationship between donors as "grandparents" and the children of donor-conceived persons is not one that is currently highlighted in German or British laws, and "donor-conceived grandchildren" have no rights to access information about their "donor grandparents". ${ }^{14}$

The significance people ascribed to telling their children and the difficulties that many anticipated illustrate that the closeness of kinship relations is conceptualised in a twofold way: on the one hand, people take into account "the strength or dilution of shared substance" (Edwards 2000: 220) when determining how closely people are related; hence, the parent-child relationship is conceptualised as being closer than the grandparent-child relationship. It is fitting that my interlocutors usually mentioned that they hoped and thought that their children would not be affected by the donor's anonymity as much as they were, since they had an unknown grandfather, but knew their father. On the other hand, "the quality and quantity of social interaction" (ibid.) can be an influential factor as well. Since they either wanted their parents to be involved in their children's lives, or because they were already very involved, this relationship was thought of as being close and important as well. They oftentimes thought about their own relationship with their donor and their father in a similar way, describing themselves as being close to the donor in terms of shared DNA and close to their father in terms of time spent together. While the donor had provided them with their genetic make-up, their father had raised them and had also had a formative influence on them. The way Sarah, who had told her own son early on, formulated her thoughts on the subject appeared in a similar form in many interviews. She argued that she had "three different people who make up me, and I've got my mom and my dad, but I can't just ignore the fact

14 This was criticised by Spenderkinder in the debates about the German sperm donor register. In their commentary on the draft bill, Spenderkinder (2017b) argued that the second generation of offspring might have a legitimate interest in accessing information, especially if the donor-conceived do not exercise their right themselves, or if information had not been passed on to their children. 
that I have 50 percent of somebody else's genes". She emphasised that her father was "completely my dad" and stressed that he was "very much a part of who I am, even though we're not genetically related".

Reassuring remarks such as "my dad is still my dad" kept reappearing in many interviews. Only very occasionally did people speak of their "social father" (sozialer Vater); if the term was used, then only very rarely, and never continuously throughout an interview. Even those who were disappointed by their parents and spoke of a breach of trust oftentimes emphasised that they were still referring to their father as "father". Timothy Parsons for example, when telling me how he had first talked with his father after being told by his mother that he was donor-conceived, said, "I'll call him my father because he is, it will not make a change, he's always my father." He and others thus denied that a genetic connection made a difference. Commenting on the kin terms used by her interlocutors, who would refuse to refer to a sibling who had another father as "step sibling", Edwards argues that "[i]t is in the denial of difference, however, that difference lies" (2000: 232). The refusal to qualify a connection "suggest[s] a resistance to the privileging of biological connection while reaffirming biological connection" (ibid.). Edwards suggests that "in order to emphasize shared substance [...] an alternative [...] is needed" (ibid.). If an alternative is evoked, then a connection can be "embraced in kin terms, whether substance is shared or not" (ibid.).

The alternative that the donor-conceived frequently evoked was the time they had spent with their fathers, and the extent to which they had had a positive impact on their lives. While the majority of people did not use the term "social father" (sozialer Vater), some did occasionally use the term "genetic father" (genetischer Vater) when talking about their donor. While the term "father" can be interpreted as an instance of them "attributing humanity to what has been called 'mere' cells" (Hertz et al. 2013: 62), I suggest that "genetic" was used to highlight that this was a qualified connection that did not match the relationship they had with those who had raised them. In contrast, the terms "donor" and "genetic parent/father" were not used, and in some cases explicitly rejected, by those who were critical of donor conception per se. According to them, those with whose gametes a child was conceived were his/her parents (section 4.1). This, too, suggests that kin terms "do more than fix and locate people in relation to each other, they also connote special types of relationship and are thought to create particular kinds of ambience" (Edwards 2000: 232).

While telling children about their "genetic grandparents" was imagined to be a difficult task especially by those who were not yet parents, children's reactions to being told were rarely commented on, possibly because most of my interlocutors who were already parents had very young children who arguably could not show much of a reaction. Those whose children were a little older sometimes mentioned that their children had simply taken note of the information and emphasised that 
it had not changed anything in the relationship between their children and their father. They saw this as an indication or proof that donor-conceived children could accept the circumstances of their conception as something completely normal if they were told about it at an early age. When people described more emotional reactions, they usually interpreted them seen as a sign that children could intuitively recognise the truth. This view is consistent with the way in which children are seen as purer and more authentic than adults, which has been an influential view in European pedagogy (see also section 5.2). An emotional response was described by Jennifer Bunton. Jennifer was very critical of donor conception per se (section 3.4), believing that a donor-conceived child "is not going to have half of their family". She mentioned that her daughter had cried when she had told her that she was donor-conceived. Her daughter said, "So you don't know who your real dad is." Jennifer concluded that "children say things quite as they are".

The desire and need to be a responsible parent, which motivated many people to be open with their own children, was also expressed in my interlocutors' wish to know their full medical history so that they would know what they, as parents, would pass on to their children. Similar to Klotz, I found that not knowing their complete medical history was usually "mentioned by informants as one genre to explore their general sense of deprivation of knowledge and injustice" (2016:51) instead of being "interrogated in medical detail" (ibid.). If a lack of medical history was a pressing concern for someone, it was mostly because they worried about their children, and not primarily because they were concerned about their own health. This was the case for Kai Silberschlag, who was a father of three and worked as a teacher. Aside from his curiosity, which was primarily focused on those characteristics that distinguished him from his family (section 5.3), his desire to learn more about his donor was also related to his desire to be a responsible father. He raised the issue when I asked him what he thought the duties of parents, the state and clinics were in terms of disclosure and the wellbeing of the donor-conceived. Kai pointed out that whereas he knew the medical history of his mother's family, he knew nothing about what had been passed on to him from his donor, and what he might therefore have passed on to his own children:

Kai Silberschlag: "I look at my mother's family, and I know there's a problem with dementia. My great-grandmother took the tram in her nightgown. And it was exactly the same with my grandmother the last few years. I'd like to know if there's anything like that. Not just because I'm worried for myself, but because I have three children. A few years ago, I had a student, she was in sixth grade, eleven years old, she had to go to cancer screening all the time, not because she had it, but because it's very common in that family. It has so far not been in my family. But what about the donor's family? I simply have three children, and I have a responsibility towards them, and I would like to be able to live up to that responsibility, 
it would be better if I knew something. When I did my community service [Zivildienst] I worked with this man, he turned blind when he was 30 , there was nothing you could do about it back then, but it was already in the family. How should I know if there is something like that? And I think that that's of course where the state could force the clinics to maybe really reveal more information because after all, there's really nothing that we know."

While he had earlier stated that a fertility clinic could only ever be a "service provider" that was not responsible for children learning of the circumstances of their conception, Kai did not believe that clinics were free of any kind of responsibility. Since they had the information that would enable the donor-conceived to fulfil their parental responsibility, he considered it justified to force them by law to release relevant information. The desire to have access to complete medical records was frequently mentioned by the adoptees interviewed by Carsten (2000b: 696-697). They, too, were interested not only in what the medical history of their birth parents meant for them but also in what this information could mean for their own children. Carsten concludes that

"Knowledge of the medical history of forebears is desired not just as a means to acquire a complete personal biography, but as something that might be transmitted down the generations. It encapsulates a history of kinship, but its significance is for the future. The difficulty is, of course, that this sense of the future is not only connected to the present, and to the future-in-the-present, but it can also not be detached from the past." (Carsten 2000b: 697)

The problem people had with 'passing on the unknown' to the next generation, regardless of whether or not their children had already been born (or conceived), is an example for how "past, past, present, and future chronologies of kinship" (Carsten 2007: 419) are intertwined. When people find out that they were conceived with donated gametes, it is not only their view of the past and present of their kin relations that changes; instead, the way they view and engage with the future is also affected. New information about their origins is thus information about past, present and future kinship.

This intertwining of chronologies is also evident in the way people would start and/or restart their search. My research suggests that the chronology of a search might be dependent on the life history of the person that is searching, which is again similar to Carsten's argument about "kinship chronologies" (2007). The adoptees Carsten interviewed had often interrupted their search for their birth parents over and over again. The decision to continue searching for them was usually linked to changes in their own family life (2007: 418). While most of my interviewees were immediately interested in finding out more about their donor, there were also several people who had only started searching years later. They often explained a 
new or renewed interest in the donor with reference to something important that had changed or happened in their life. Moving out of the family home and starting one's own family (see also the experience of Sabrina Frey, as described in section 5.3) were usually the events that were described as such turning points. Sarah, who had learnt of the circumstances of her conception at the age of 13, explained that "it's been significant bits in my life that made me readdress who I am and my identity", such as the beginning of her studies, her wedding, and the birth of her first child. These events had coincided with further steps in her search, such as the purchase of a DNA test, without Sarah necessarily being aware of this connection at the time. Many of my interviewees believed and/or hoped that donors would make a similar experience. While some believed that donors would not be interested in them and argued that they had only donated for the money, others reasoned that donors would become interested in their donor offspring when they had their own children. ${ }^{15}$ While the intertwining of kinship chronologies could mean that anonymity was perceived as problematic because it prevented people from being responsible parents, it also forestalled the expectation of kinship trouble with regards to the donor.

\subsection{Recapitulation}

While many of the donor-conceived persons I interviewed did not learn about the circumstances of their conception until adulthood, in most cases their parents had already told relatives or friends. Thus, others within or outside the family had already been in possession of information that my interviewees considered to be of central importance for their own lives. This was described as a painful breach of trust. At the same time, those whose parents had not told anyone worried about their parents' adherence to secrecy. Especially those who did not oppose donor conception often regretted that their parents were not open about their treatment. They argued that men who raised a "foreign child" should be proud of their willingness to do so and interpreted the unknown origins of a child as something that required a lot of courage from parents. They admired their parents and especially their fathers, as they had not been deterred by the prospect of experiencing kinship trouble.

The donor-conceived themselves were usually very careful not to cause any such trouble and thought carefully about whom to tell, and whom not to tell. The ideal

15 A study conducted on the experiences of five German sperm donors suggests that the way in which donors interpret their donation might indeed change over time, and that "sperm donation is connected with wishes, ideas and experiences in the field of reproduction" (Baumeister-Frenzel et al. 2010: 108, author translation). 
of absolute and unconditional openness was less important than considerations of care when people made that decision. A concrete case of intra-family trouble existed for those whose siblings did not yet know that their parents had conceived their children with donated gametes. They had information that was constitutive for their siblings but that they did not want to share with them on their own. Those for whom this was the case described these situations as extremely difficult and challenging. They wanted their parents to take over the telling and ensure an even distribution of knowledge. If siblings have different donors, the sibling relationship may stay uneven once everybody has been told, as one sibling might be able to find out more than the other. Nevertheless, it was usually described as advantageous to have a different donor. My interviewees hoped that this would ensure that a sibling with less interest in finding out more would not be affected by their brother's or sister's search for information. Another case of actual or anticipated kinship trouble was the sharing of information with their own children and the negative effect the donor's anonymity was expected to have on them. While there was a strong tendency to tell, people were not always sure what to do: on the one hand, the donor-conceived did not want to interfere with their children's relationship with their grandparents. On the other hand, they did not want to withhold information about their origins and their "genetic grandparent" or "donor grandparent". They were guided in their decisions not only by the ideal of openness and honesty but also by concerns about relationships, and they wanted to be responsible parents as well as good daughters and sons. 
